\title{
A Reforma Tributária como Instrumento de Efetivação da Justiça Distributiva: uma abordagem histórica
}

\author{
Tax Reform as an Instrument for the Effectiveness of Distributive Justice: a \\ historical approach
}

\author{
Carlos Henrique Machado \\ Universidade Federal de Santa Catarina - Florianópolis, SC, Brasil \\ Ubaldo Cesar Balthazar \\ Universidade Federal de Santa Catarina - Florianópolis, SC, Brasil
}

\begin{abstract}
Resumo: O artigo pretende realizar uma reflexão sobre a real necessidade de uma reforma tributária no Brasil e sua utilização como instrumento de realização de justiça distributiva. Para tanto, são analisadas as fontes doutrinárias que buscam compreender as razões e a história da tributação, noções fundamentais para que se possa mensurar os limites toleráveis que cada sociedade admite suportar a título de exação tributária. Num segundo momento, aborda-se o bem comum como legitimação de uma tributação justa, levando-se em consideração que a causalidade entre tributação e o bem comum, numa perspectiva aristotélica, sempre foi uma constante histórica, evoluindo tão somente a própria concepção de bem comum a justificar a tributação e os métodos de imposição e de arrecadação físcal. A formação do sistema tributário brasileiro dos tempos do Brasil Colônia, perpassando pelo período imperial e pelas constituições republicanas, também é objeto de atenção e de entraves que sofre o modelo atual do sistema tributário nacional. Tal estudo é necessário para buscar, por meio de uma reforma tributária, as alternativas para a melhor efetivação dos direitos fundamentais.
\end{abstract}

Palavras-chave: História do Tributo. Reforma Tributária. Justiça Distributiva.
Abstract: The article intends to reflect on the real need for a tax reform in Brazil and its use as an instrument for the realization of distributive justice. In order to do so, the doctrinal sources that seek to understand the reasons and the history of taxation are analyzed, which are fundamental notions to measure the tolerable limits that each society admits to bear as tax exoneration. Secondly, the common good is approached as the legitimacy of a fair taxation, taking into account that the causality between taxation and the common good, from an Aristotelian perspective, has always been a historical constant, evolving the very conception of the common good to justify taxation, as well as methods of tax rebates and collection. The formation of the Brazilian tax system, from the colonial period in Brazil, passing through the imperial period and the republican constitutions, is also an object of attention, as well as the obstacles that undergo the current model of the national tax system. Such study is necessary to search, through a Tax reform, the alternatives for the best realization of fundamental rights.

Keywords: Tax's History. Tax Reform. Distributive Justice.

Recebido em: 13/07/2017

Revisado em: 19/09/2017

Aprovado em: 10/10/2017 


\section{Introdução}

A História tradicional, caracterizada pelo estudo de grandes eventos, costuma dividir a existência humana em períodos distintos, marcados por descontinuidades. Com a História do Direito não é diferente. Recentemente, o Código Tributário Nacional completou cinquenta anos de existência, constituindo um importante acontecimento para o Direito Tributário brasileiro. Ao longo de sua vigência, a atividade de tributação conviveu com momentos políticos distintos e experiências sociais importantes, mantendo-se o diploma legal firme e resistente para desempenhar um relevante papel junto à sociedade. Desde a sua edição, no entanto, anseios por reformas nos métodos e instrumentos de tributação sempre foram frequentes. E isso é bastante compreensível, na medida em que conjunturas socioeconômicas diversificadas exigem a adoção de ações político-jurídicas diferentes, cuja evolução caminha no ritmo das novas demandas e necessidades sociais.

Compreender as razões e a história da tributação é fundamental para que possam ser mensurados os limites toleráveis que cada sociedade admite suportar a título de exação tributária. Numa concepção moderna, não há Estado sem tributação. Isso é inegável. A arte da tributação, todavia, consiste em saber retirar as penas do ganso com o mínimo de dor possível, conforme a célebre frase atribuída a Jean-Baptiste Colbert, ministro das Finanças do Rei Luís XIV, da França (LIMA, 1999, p. 5-6). E essa é justamente a razão que sempre transforma o debate sobre a tributação numa discussão paralela a respeito do modelo social que os cidadãos almejam, sobre o tamanho do Estado e sua parcela de intervenção na riqueza dos particulares.

Foi apenas no fim do século XVIII que a tributação passou a receber uma maior atenção de influentes políticos, economistas e financistas europeus e americanos, quando começaram as manifestações e preocupações com um sistema de arrecadação mais justo e racional (BALTHAZAR, 2005, p. 21). Mas foi somente em meados do século XIX, contudo, que os estudiosos dedicaram maior cuidado ao fenômeno especificamente jurídico da tributação (BECKER, 2007, p. 3). Estavam sendo construídos, fi- 
nalmente, os alicerces para a construção dos processos de aprimoramento dos mecanismos de arrecadação.

A ideia de reforma tributária, portanto, não deve ser entendida como um fenômeno exatamente contemporâneo. Desde sempre se efetivaram mudanças nos critérios e procedimentos de arrecadação tributária, com avanços mais ou menos intensos em termos de proteção dos direitos individuais, e mesmo com alguns retrocessos. O paradigma reformista, assim, não é novidade alguma. Pelo contrário. Transformam-se apenas as razões que impulsionam as mudanças. Se é verdade que muitos dos avanços físcais do passado ocorreram em razão de discussões a respeito da legitimação ou majoração das elevadas cargas tributárias, atualmente as motivações por detrás das propostas de modificação não são outras senão as de amoldar o tributo exigido pelos Estados às contrapartidas oferecidas aos contribuintes. Noutras palavras, busca-se pela realização de reformas tributárias a efetivação da justiça social.

Atualmente, no Brasil, a temática da reforma tributária tem sido cada vez mais recorrente, sobretudo quando o assunto em pauta é o sistema tributário nacional. Entretanto, malgrado existam algumas propostas de reformulação tributária pendentes no Congresso Nacional, é ainda flagrante a desídia dos legisladores ordinários no enfrentamento e avanço do problema, o que transforma a mera letargia política num problema que se agrava constantemente, corporificando as desigualdades sociais e o chamado "custo-Brasil". Por isso, ladeada pelo rearranjo do sistema político, a reforma tributária tem sido frequentemente invocada e simbolizada como a solução de muitas das mazelas da sociedade brasileira na atualidade.

O intuito do presente ensaio, sem o propósito de apresentar uma solução para o problema hercúleo que assola o sistema tributário nacional, restringe-se a perpassar algumas passagens históricas do Direito Tributário, no Brasil e no mundo, bem como entender os reflexos produzidos na legislação atual, sem perder de vista a análise das principais características do obsoleto modelo de tributação vigente. 


\section{O Bem Comum como Legitimação da Tributação Justa}

A causalidade entre tributação e bem comum, numa perspectiva aristotélica, sempre foi uma constante histórica, evoluindo tão somente a própria concepção de bem comum a justificar a tributação, bem como os métodos de imposição e arrecadação fiscal. Durante a Antiguidade, já houve tempos em que os Estados obtinham os seus recursos por meio de hostilidades e guerras, exigindo reparações patrimoniais dos perdedores em consequência das despesas havidas com os combates (BALTHAZAR, 2005 , p. 20). Em épocas mais recentes, as cobranças mantiveram-se atreladas essencialmente ao poder tirano dos Soberanos, exigidas sobre uma parcela da produção de seus súditos. Atualmente, é por meio de tributos que os Estados modernos exigem do seu povo os recursos necessários para aplicá-los em serviços públicos e buscar as melhorias sociais, assim suportando os gastos contraídos em nome da coletividade. Significa dizer, pois, que os tributos são, e sempre foram, expressão clara de poder.

A ideia de justiça tributária, como a própria concepção de justiça em si, traduz um conceito evidentemente complexo. Norberto Bobbio, Nicola Matteucci e Gianfranco Pasquino (2010, p. 660-661) sustentam que a justiça é um fim social, assim como a igualdade, a liberdade, a democracia ou o bem-estar. Para eles, sendo um conceito normativo, surge a dificuldade de definir a justiça em termos descritivos. Ao longo de toda a História, alguns grandes expoentes da Filosofia e do Direito buscaram o enfrentamento da temática, sendo farta a literatura sobre o assunto, a partir de filósofos como Platão e Aristóteles, passando por autores como Hobbes e Montesquieu, até encontrar pensadores como Hans Kelsen, Herbert Hart, Stuart Mill, John Rawls e tantos outros (BOBBIO; MATTEUCCI; PASQUINO, 2010, p. 660-666). De modo geral, porém, costuma-se adotar a distinção aristotélica entre justiça distributiva e reparadora, sendo a primeira, normalmente associada às teorias de direito tributário, aquela que se exterioriza na distribuição de honras, de bens materiais ou de qualquer coisa divisível entre aqueles que integram o sistema político. Diversamente, a justiça reparadora está mais especificamente ligada a situações em que alguém, ao receber uma ofensa, exige a consequente reparação (BOBBIO; MATTEUCCI; PASQUINO, 2010, p. 662). É cediço, 
contudo, que, para delinear com melhor precisão o conceito de justiça, é fundamental demarcar o seu significado no tempo e contextualizá-lo com os diferentes valores que the cercam, como a legalidade, a segurança, a liberdade, a previsibilidade etc.

No âmbito do direito tributário, também não é de hoje que filósofos, economistas, sociólogos e juristas ocupam o seu tempo tentando abrandar inquietações teóricas e buscando encontrar as melhores respostas sobre o tributo justo. Santo Tomás de Aquino, teorizando sobre a justiça da lei humana a partir da imposição de limites ao poder soberano, dissera que “[...] tudo aquilo que é em razão de um fim, é necessário que seja proporcionado ao fim”. Para ele, o fim da lei é o bem comum, pois, aludindo Isidoro, "[...] a lei deve ser escrita não em vista de um interesse privado, mas a favor da utilidade comum dos cidadãos" (AQUINO, 2005, p. 583584). Logo, as leis impostas humanamente ou são justas, ou são injustas. Segundo a teoria tomista, as leis são justas: em razão do fim, quando são ordenadas ao bem comum; em razão do autor, quando a lei promulgada não ultrapassa a autoridade de quem a promulga; e em razão da forma, quando, conforme a igualdade de proporção, são impostas aos súditos obrigações quanto ao bem comum. Assim, quando são justas, têm força de obrigar no foro da consciência pela lei eterna, da qual derivam. Tais leis, desse modo, trazendo obrigações proporcionais, são justas e, portanto, são leis legais (AQUINO, 2005, p. 589-590). Nessa linha de pensamento medieval, considera-se lei apenas aquilo que seja justo. Trata-se de uma concepção de bem comum que penetrou no imaginário tributante, usada como causa de legitimação da arrecadação, perdurando até os dias recentes.

Com o advento da teoria do benefício, no século XVII, o bem comum passou a identificar-se com algum benefício identificável ou determinado ao contribuinte, sendo justa a exação quando o esforço (custo) é equivalente à contrapartida auferida. Autores como Grotius, considerado o precursor da teoria, além de Pufendorf, defenderam inicialmente o princípio como sinônimo de justiça, assim definido por Musgrave: "Sob um regime estrito de tributação de acordo com o princípio do benefício, cada contribuinte seria tributado de acordo com sua demanda por serviços públicos" (PESSÔA, 2008, p. 4.870). É interessante notar que o princípio do 
benefício é responsável pelas linhas conceituais preliminares a respeito daquilo que atualmente se compreende como taxa pública, na condição de tributo com natureza vinculada, justificando-se pela lógica de que o beneficiário direto de serviços públicos deve arcar com os seus custos. O princípio do benefício não tem aplicabilidade em relação aos impostos, porque não é possível, nesse caso, uma mensuração individualizada e específica do proveito auferido por cada contribuinte. Por esse motivo, a teoria restará abandonada há algumas décadas, conforme demonstra a abundante doutrina italiana.

Filósofos do período contratualista, durante o século XVIII, difundiram a ideia de que todos os indivíduos deveriam contribuir para a formação da República (res publica), consolidando-se uma conotação ética da tributação. Diante do estado de natureza de guerra de todos contra todos (bellum omnium contra omnes), autores como Hobbes, Locke e Rousseau passaram a sustentar que se torna mais leve individualmente aquilo que é coletivamente suportado por todos. Hobbes dizia que tudo aquilo que é válido para o tempo de guerra, quando todo homem é inimigo de todo homem, o mesmo é válido para o tempo durante o qual os homens vivem sem outra segurança senão a que lhes pode ser oferecida apenas por sua própria força e sua própria invenção. Nessa tal situação, a teoria hobbesiana sustenta que não existe sociedade, sendo a vida do homem solitária, pobre, sórdida, embrutecida e curta (HOBBES, 2003, p. 109). Foi justamente nesse ambiente, propício à formação das coletividades, que se impulsionou o desenvolvimento de uma ideia de bem comum ínsita à razão de Estado (ius imperi), ainda hoje amplamente difundida para justificar a tributação, e cujo monopólio de uma violência legítima por parte do Soberano pode ser extraído da obra Leviatã.

Adam Smith, na segunda metade do século XVIII, tratou de quatro máximas a respeito dos impostos em geral, desenvolvidas no escrito de "A Riqueza das Nações: Investigação sobre sua Natureza e suas Causas". Segundo o Smith, no pensamento daquele tempo, todo o imposto deveria, em última análise, ser pago sobre a renda, o lucro e os salários, ou sobre todas essas bases. Para tanto, Smith aconselhava a atenção de todas as nações para quatro regras fundamentais, em razão da evidente justiça e da utilidade do seu método, em maior ou menor grau: os súditos de cada 
Estado devem contribuir o máximo possível para a manutenção do Governo, na proporção das suas respectivas capacidades, isto é, proporcionalmente ao rendimento que cada um desfruta, sob a proteção do Estado (a equidade); o imposto que cada indivíduo é obrigado a pagar deve ser fixo e não arbitrário (a certeza); todo imposto deve ser recolhido no momento e da maneira que, com maior probabilidade, forem mais convenientes para o contribuinte (a comodidade); todo imposto deve ser planejado de tal maneira que retire e conserve fora do bolso das pessoas o mínimo possível, além da soma que ele carreia para os cofres do Estado (a economia) (SMITH, 1996, p. 282-283).

Ainda durante esse período, próximo à virada do século XVIII, Wilhelm von Humboldt desenvolveu uma teoria sobre os limites da ação do Estado, a partir da noção da "certeza da liberdade sob a lei". Para o autor, a verdadeira finalidade do homem, que se encontra prescrita pelos imperativos da razão eterna e imutável, é a de formação mais alta e harmoniosa possível de suas forças em direção a uma totalidade completa e consistente (HUMBOLDT, 2004, p. 143). Conhecido como teórico da liberdade, von Humboldt propõe que cidadãos estão seguros, em relação ao Estado, quando, vivendo juntos e em pleno gozo dos seus direitos pessoais e da propriedade, encontram-se fora do alcance de perturbação externa, a certeza da liberdade legal (HUMBOLDT, 2004, p. 262). Não obstante, mesmo para realizar os seus objetivos mais limitados, o Estado precisa dispor de receitas suficientes, que podem ser apenas três: a propriedade que tem sido reservada ao Estado ou adquirida; os impostos diretos; e os impostos indiretos. De todas as possibilidades, o autor defende que a taxação direta é tudo o que resta. Humboldt observa que o Estado não necessita de grandes receitas, justamente porque não possui interesses especiais voltados para si mesmo, além daqueles dos seus cidadãos, de modo que o Estado resultará mais garantido exatamente pelo apoio de uma nação livre (HUMBOLDT, 2004, p. 337-339).

Como evolução do princípio de equivalência, desenvolveu-se a teoria do sacrifício, servindo de sustentação teórica para alguns postulados modernamente difundidos, como a capacidade contributiva e seus corolários, a exemplo da proporcionalidade, da progressividade e da seletividade. Autores como John Stuart Mill, já no século XIX, passaram a 
defender a necessidade de cada indivíduo contribuir para a coletividade na medida das suas possibilidades econômicas. A ideia de verticalização da justiça irrompe francamente no momento em que surge uma pequena burguesia, fomentando a incipiente formação dos Estados modernos, ao sugerir a necessidade de atender serviços elementares em prol dos indivíduos. A moral utilitarista, segundo Stuart Mill (1984, p. 65), “[...] reconhece ao ser humano o poder de sacrificar os seus próprios interesses pelos interesses dos outros". Para ele, o próprio sacrifício já é um bem por si mesmo (MILL, 1984).

O chamado Período Clássico, ligado ao Liberalismo dos séculos XVIII e XIX, caracterizou-se principalmente pelo princípio do não intervencionismo, em que os Estados se limitavam a desempenhar o mínimo possível de atividades, com caráter de essencialidade, deixando todas as demais para a iniciativa privada. Já a partir dos fins do século XIX, porém, aconteceu o alargamento das ações do Estado, que deixou de ser um mero expectador da atividade econômica, passando a intervir de modo mais ativo junto à sociedade, impulsionado pela Revolução Industrial, pelos avanços científicos e pela escalada do desemprego (ROSA JR., 2007, p. 02-05). Desses tempos, decorre um dos grandes legados para a Ciência das Finanças dos dias atuais, caracterizada justamente pelo caráter intervencionista do Estado, por meio da autoridade da imposição tributária. Aludindo Maurice Duverger, Rosa Júnior explica que o Estado contemporâneo pode adotar quatro formas para proceder ao intervencionismo fiscal: a) intervenção pelo aumento ou diminuição da carga tributária global; b) intervenção mediante discriminação; c) intervenção por amputação; e d) intervenção por redistribuição (ROSA JR., 2007, p. 7-8). Costuma-se demarcar exatamente nessa segunda metade do século XIX a consolidação da autonomia da Ciência das Finanças (BALEEIRO, 2010, p. 20), mas mesmo em épocas mais remotas, no final do século XVIII, já era possível considerar existente um núcleo de princípios basilares sobre as finanças públicas, ainda que numa perspectiva econômica, e não de ordenação jurídica (BECKER, 2007, p. 3). Conforme lembra Ricardo Lobo Torres, é apenas no final do período do absolutismo que a legalidade vai surgir como limitação do poder do rei e garantia da fiscalidade periférica e da justiça, como bem-comum, em sentido escolástico, definindo-se 
o tributo justo como o exigido para atender às necessidades públicas (TORRES, 1991, p. 14).

O século XX ficou marcado por intensas reformulações sociais, especialmente ocorridas após o final da Segunda Guerra Mundial, diante de horrores legais praticados pelo regime do nazismo, estabelecendo uma nova doutrina de direitos humanos, consubstanciada em um conjunto de valores de proteção do homem, que o colocam no centro do sistema jurídico. É do início desse século, no entanto, o primeiro Código de Normas de Finanças (reichsabgabenordnung), datado de 1919, cujo articulista é o alemão Eno Becker (BALEEIRO, 2010, p. 39). Esse novo paradigma jus filosófico passou a estabelecer que o Estado não é a lei, mas, igualmente, submete-se a ela e ao Direito, em especial a partir da incorporação formal das garantias fundamentais e dos instrumentos de efetivação dos direitos individuais no corpo dos textos constitucionais, que, ademais, alavancaram a relevância institucional do Poder Judiciário, com um papel mais ativo no controle de constitucionalidade.

A nova dogmática dos direitos humanos confirma que o imposto deixa de ser uma forma de opressão da liberdade, passando a representar o próprio preço da liberdade, como defende Ricardo Lobo Torres (1991, p. 83). Nessa mesma linha, Renato Lopes Becho aduz que o direito tributário perde o seu significado de conjunto de normas que meramente visam à arrecadação, objetivando, por outro lado, a proteção dos cidadãos-contribuintes. Para Becho, as normas procuram fazer da arrecadação um ato de poder jurídico, e não policial, resguardando o homem em sua dignidade (BECHO, 2009, p. 308). Trata-se de uma conotação ética da tributação.

\section{Breves Notas sobre a Formação do Sistema Tributário Brasileiro}

Não é um exagero afirmar que a história da tributação se confunde com a própria história dos Estados, como sociedades organizadas. O surgimento dos tributos, revestidos de uma concepção mais aproximada do modelo atual, é produto das revoluções liberais (1640, 1779 e 
1789), notadamente da Revolução Industrial, impulsionada pelos ideais da Revolução Francesa, malgrado a materialização prática da tributação tenha se reforçado com aparecimento dos Estados Nacionais. No Brasil, em especial, esse fenômeno aconteceu de forma bastante similar. Apesar disso, desde a descoberta do país, já havia algum convívio com taxações e exações expropriatórias, edificando-se daí os fundamentos estruturantes da disciplina moderna das relações jurídico-tributárias.

O direito tributário brasileiro encontra as suas raízes mais profundas no conjunto das normas portuguesas vigentes na época do descobrimento, que exerceu uma inegável influência na formação cultural do ordenamento jurídico pátrio. Ubaldo Cesar Balthazar (2005, p. 32) explica que, se nesse tempo já havia um "direito tributário", não existia ainda, por outro lado, um "sistema tributário", assim compreendido como um conjunto harmônico de princípios, regras e institutos disciplinadores da atividade tributária, cujo elemento nuclear é o tributo. Desde o começo do período colonial, marcado pela imposição da legislação lusitana nas terras desbravadas, e então submetidas aos ordenamentos da Coroa portuguesa, começaram a ser criados os primeiros tributos vigentes em chão brasileiro. $\mathrm{O}$ quinto, ou vintena, passou a ser exigido logo nas primeiras décadas do século XVI, incidindo sobre os produtos extraídos das possessões d'além-mar, notadamente a extração do pau-brasil.

As bases da tributação nas terras descobertas, que surgiram atreladas aos interesses extrativistas da Coroa, sofreram um grande incremento durante todo o Período Colonial. Com o recrudescimento da política tributária, a partir de meados do século XVIII, motivado por interesses ligados ao crescimento populacional e ao avanço desenvolvimentista, aconteceu o mais forte acirramento da arrecadação. A transição da população rural para os centros urbanos alavancava as necessidades coletivas relacionadas à prestação de serviços essenciais de saúde e segurança. Paralelamente, não interessava a Portugal a capacidade contributiva dos colonos, mas tão somente o desejo de amenizar o déficit da balança comercial com a Inglaterra (BALTHAZAR, 2005, p. 55), tornando-se a tributação cada vez mais opressiva e violenta. $\mathrm{O}$ agravamento da rigidez fiscal viria a deflagrar, alguns anos depois, um período de graves revoltas e inquieta- 
ções populares, dentre as quais a Conjuração Mineira, em 1789, é o acontecimento mais famoso e conhecido.

Mesmo com o deslocamento da Família Real para o Brasil, em 1808, a conturbação social permaneceu incontida, culminando na Proclamação da Independência, em 1822, seguida do Período dos Reinados, bastante fecundos em matéria de imposição fiscal. Somente com o advento da primeira Constituição brasileira, de 1824, alicerçada no modelo das monarquias constitucionais europeias, consolidou-se o Estado Fiscal no Brasil, porém ainda com poucas normas sobre a tributação e sem solução para o problema das competências das rendas (BALTHAZAR, 2005, p. 79). Segundo Ricardo Lobo Torres, a partir da Carta Imperial de 1824, solidificou-se uma nova estrutura da receita pública, na qual os impostos e os empréstimos passaram a ocupar o lugar principal, separando-se, contudo, a Fazenda do Imperador e a Fazenda Pública. Por outro lado, salienta Torres, mantiveram-se diversos dos condicionamentos do patrimonialismo, seja pela inexpressividade da burguesia ou pelo exagerado intervencionismo estatal na economia, malgrado essa situação não tenha sido privativa da cultura luso-brasileira, porquanto fora também vivenciada por outros países que superaram o Estado de Polícia, como Alemanha, Itália e Áustria. (TORRES, 1991, p. 149). Nessa época, na esteira da Lei n. 58, de 1833, e da Lei n. 99, de 1835, restara editada a Lei Orçamentária n. 108, de 1840, que fixou a nova discriminação legal dos tributos, classificando-os em Receitas Gerais, Provinciais e Municipais (BALTHAZAR, 2005, p. 88-89).

Com a Proclamação da República, ocorrida em 1889, iniciou-se, enfim, uma nova Era de físcalidade no Brasil. São desse período os primeiros estudos financeiros do direito pátrio, que consagraram o jurista Rui Barbosa, à época, como um dos grandes financistas brasileiros, notadamente com a publicação do Relatório do Ministério da Fazenda, em 1891 (BALEEIRO, 2010, p. 23). A Constituição de 1891, inspirada na Constituição dos Estados Unidos da América do Norte, ainda sob as luzes da herança lusitana, abriu os caminhos para o federalismo no Brasil. Em face da exigência crescente de tributos e da falta de racionalidade do sistema fiscal, a Carta de 1891 optou por um modelo rígido de tributação, mas ainda permitindo a superposição dos tributos locais e centrais, muitas 
vezes redundando em odiosa bitributação, além de não contemplar os municípios na discriminação de rendas (ZAVARIZI, 2006, p. 128).

A Constituição de 1934, calcada na Carta de Weimar, prescreveu a nova discriminação de rendas tributárias, finalmente agraciando os municípios com impostos privativos. Sua vigência, porém, foi bastante reduzida, notadamente em razão da outorga da Constituição de 1937, com a sua índole tipicamente autoritária. No final da década de 30, a divulgação de informações dos orçamentos públicos brasileiros, representativas da arrecadação tributária global no país, expunha a efetiva participação de cada um dos entes federativos no volume total de receitas auferidas, cabendo à União uma parcela de 52,81\% da arrecadação; aos Estados, de 29,25\%; aos Municípios, de 10,81\%; e ao Distrito Federal, de 7,13\%. Analisando especificamente esse cenário, Alcântara Machado observara que tamanha era a concentração de receitas no Brasil, que, para qualquer estudioso de Finanças, o país mais pareceria um Estado Unitário do que uma Federação, fato que explicaria em grande parte as graves mazelas que acometiam a população brasileira daquele tempo. Segundo ele, resultava exatamente daí uma vida meramente vegetativa da imensa maioria dos municípios brasileiros, que apodreciam ao sol, feridos de paralisia e incapazes de proverem as suas próprias necessidades mais elementares (ZAVARIZI, 2006, p. 134-135). Ironicamente, de lá para cá, passados cem anos, pouquíssima coisa mudou.

O Direito Tributário somente se consolidaria como disciplina autônoma, adquirindo foros de matéria jurídica, com princípios, regras e institutos próprios, após a Segunda Grande Guerra Mundial, em 1945, depois do vertiginoso desenvolvimento dos Estados e da sua crescente participação na economia (BALTHAZAR, 2005, p. 23). No Brasil, com o advento da Constituição de 1946, iniciou-se finalmente o ciclo de formação de um sistema tributário propriamente dito. Nesse período, Alfredo Augusto Becker dizia, com a sua peculiar ironia, que o sistema tributário brasileiro era a típica representação do Carnaval, estruturado de acordo com a forma e a cor das estampilhas (BECKER, 1999, p. 13). Segundo Becker, um severo crítico da infeliz mancebia entre o Direito Tributário e a Ciência das Finanças Públicas, o que ocorria no Brasil, tal como se observava na maioria dos países, era o mesmo fenômeno patológico-tributário, carac- 
terizado por uma situação de confusão total e orgia, em que a segurança jurídica encontrava-se perdida na "maraña legislativa", cujo impulso fanático fomentava a proliferação de leis tributárias (BECKER, 2007, p. 6).

A Carta de 1946 modificou sensivelmente a discriminação de rendas tributárias no Brasil, buscando solucionar os problemas de finanças locais, mas não tratou de promover uma sistematização completa do direito tributário brasileiro (ZAVARIZI, 2006, p. 139). A racionalização do cipoal de leis tributárias era uma medida vindicada amplamente pelos mais renomados estudiosos da matéria, a ponto de Alfredo Augusto Becker dizer que qualquer jurista daquela época, se refletisse sem orgulho e preconceito, dar-se-ia conta de que circulava nos corredores de um manicômio jurídico-tributário (BECKER, 2007, p. 6). Foi nesse contexto, no ensejo do crescente desenvolvimento da Ciência das Finanças, que acabou publicada a Lei n. 4.320, de 1964, estatuindo as normas gerais de direito financeiro para elaboração e controle dos orçamentos.

Somente com o advento da Emenda Constitucional n. 18, de 1965, porém, impulsionada pela tomada do poder pelo Governo Militar, que uma profunda reforma tributária foi realmente efetivada no Brasil, nascida sob a responsabilidade da Comissão de Reforma do Ministério da Fazenda. É considerada por muitos juristas a mais ampla e profunda reforma tributária já realizada na história do constitucionalismo pátrio, descortinando um sistema tributário moderno, enxuto e eficiente (BALTHAZAR, 2005, p. 23). Antônio Roque Carrazza explica, a respeito do tema, que a ideia de sistema resulta de uma reunião ordenada de várias partes que formam um todo, de maneira que elas se sustentam mutuamente e as últimas explicam as primeiras. Segundo Carrazza, aquelas que dão razão as outras denominam-se princípios, sendo o sistema tanto mais perfeito quanto em menor número eles existam (CARRAZZA, 2010, p. 43). A Reforma de 1965 teve como grande mérito a alteração da discriminação de competências e a classificação dos impostos sob uma visão econômica, e não mais jurídica, promovendo um maior entrosamento entre os sistemas tributários federal, estadual e municipal, de modo a instituir um integrado sistema tributário nacional (BALTHAZAR, 2005, p. 137). Foi também nesse período, com a publicação da Lei n. 4.729, de 1965, que a sonegação fiscal resultou formalmente transformada em crime no Brasil. 
Pouco tempo depois da efetivação da Reforma de 1965, restou publicada a Lei n. 5.172, de 1966, capitaneada pelos juristas Oswaldo Aranha e Rubens Gomes de Sousa, que tratou de introduzir uma disciplina ampla para o Sistema Tributário Nacional, além de instituir as normas gerais de direito tributário aplicáveis à União, aos Estados e aos Municípios. Depois de alguns meses, o Ato Complementar n. 36, de 1967, tratou de estabelecer que a então Lei n. 5.172, de 1966, bem como as suas alterações posteriores, passariam a denominar-se "Código Tributário Nacional", que recentemente completou 50 anos vida, sendo objeto de várias celebrações. O códex fiscal promoveu a extinção de diversos tributos, representando uma importante conquista para o disciplinamento da matéria. Curiosamente, contudo, parcela de seu texto nem sequer alcançou o cenário jurídico. Alfredo Augusto Becker lembra, ao render merecidas homenagens a Rubens Gomes de Sousa, autor do Anteprojeto do Código e redator do seu Projeto Final, que o Diploma de Direito Tributário sofreu com as dezenas de costumeiras alterações, já nascendo anacrônico. Dentre as várias modificações introduzidas, Becker destacou as mudanças referentes ao imposto estadual sobre a circulação de mercadorias, cujo capítulo original jamais entrou em vigor, sendo substituído por uma sequência de decretos-leis, atos institucionais "e outros atos pornográficos" (BECKER, 2004, p. 53).

A Constituição de 1967 confirmou a Reforma Tributária de 1965, consolidando um modelo sistêmico de disciplina da tributação, erigido com status de legislação constitucional. Pode-se perceber, dessa maneira, que o tratamento da legislação tributária como um sistema é algo ainda relativamente novo no ordenamento brasileiro. A Emenda Constitucional $n^{0} 01$, de 1969 , por sua vez, não operou significativa modificação na discriminação de rendas distribuídas pela Constituição de 1967. Foi também nesse período, com a edição do Decreto n. 63.659, de 1968, que restou definida a estrutura e as atribuições da Secretaria da Receita Federal, consolidando os antigos órgãos do Ministério da Fazenda, cujas atribuições estavam especificamente voltadas para as rendas internas, as rendas aduaneiras, o imposto de renda e a arrecadação em geral. O novo órgão promoveu a reestruturação da Administração Tributária, ocorrida poucos dias antes da decretação do Ato Institucional n. 5, 1968, marcando o mais 
duro golpe militar na democracia brasileira e conferindo poderes quase absolutos ao regime da Ditadura. Sob o pretexto de conter o déficit do Tesouro Público, o Ato Institucional n. 5 autorizou a adoção de medidas excepcionais, como a suspensão de direitos e garantias constitucionais, além de permitir ao Presidente da República a decretação do confisco de bens. Curiosamente, foi ainda nessa quadra da História, com a publicação do Decreto n. 1.024, de 1969, que restou extinta a famigerada quota-parte percebida por servidores públicos federais, calculada sobre multas, importâncias oriundas de leilão de mercadorias, percentagens sobre a cobrança de dívida ativa da União pagas pelos devedores, ou qualquer importância sobre valores da receita federal. Recentemente, com o advento da Medida Provisória n. 765, de 2016, autorizou-se novamente o pagamento de bônus a auditores da Receita Federal, restabelecendo-se um temerário sistema de participação da autoridade fiscal nos resultados da arrecadação.

Em entrevista concedida recentemente, o ex-Ministro da Fazenda do Regime Militar, Antônio Delfim Netto, relatou que foi conduzida, durante todo o período da Ditadura, uma reforma tributária que durou cerca de vinte e cinco anos. Em 1973, conforme aponta Delfim Netto, o Brasil era citado pelo Banco Mundial como um exemplo nessa área de administração das contas públicas (DELFIM NETTO, 2014). Por certo, no entanto, se é verdade que alguns avanços em matéria tributária foram realmente possíveis durante o Governo Militar, é também inegável que as medidas somente foram implementadas graças à mão de ferro e aos domínios tiranos nos tempos de exceção, quando as reformas eram efetivadas de maneira despótica e impositiva.

As décadas de 1970 e 1980 marcaram o período do Regime Militar e a sua derrocada a partir do processo de redemocratização do Brasil, cujo ápice ocorreu com a promulgação da Constituição da República Federativa do Brasil (CRFB), em 1988, alcunhada de "Constituição Cidadã" por Ulysses Silveira Guimarães. Foi nesse momento que acabou publicada a Lei n. 6.830, de 1980, dispondo sobre a cobrança judicial da Dívida Ativa da Fazenda Pública, conhecida como a "Lei de Execução Fiscal". É, ainda hoje, o principal instrumento utilizado pelas Fazendas Públi- 
cas de todo o país para a exigência de passivos tributários, apesar de sua grande ineficiência.

Apesar de avanços empreendidos pela CRFB, o sistema tributário nacional não resistiu a severas críticas desde o seu nascimento, tamanha é a sua complexidade e ineficiência, atualmente refletida em altíssimos custos, elevada carga e insegurança incomensurável. Ives Gandra Martins, logo após a publicação do texto constitucional, apontava que, do ponto de vista econômico, o sistema tributário era inflacionário; do ponto de vista jurídico, imperfeito; e do ponto de vista político, tirânico. Dizia Martins que o sistema tributário poderia mesmo representar o necrológico da Democracia, na medida em que, aumentando consideravelmente as obrigações dos contribuintes, desestimulava a poupança, o trabalho e o investimento (ZAVARIZI, 2006, p. 152). Aparentemente, pelo menos, a crítica doutrinária demostrou-se um vaticínio e o tempo não poupou o texto magno de sofrer com diversas modificações, confirmando-se a tendência reformista que assola o ordenamento constitucional brasileiro atual. Mesmo diante da mais relevante das alterações, introduzida pela Emenda Constitucional n. 42, de 2003, não foi possível afirmar que aconteceu a tão desejada reforma tributária brasileira. Como bem lembra Ubaldo Cesar Balthazar (2005, p. 13-14), foi uma reforma bastante tímida, um verdadeiro ajuste fiscal, visando resolver alguns dos problemas imediatos do Governo Central. Curioso ilustrar, paralelamente, que a Constituição dos Estados Unidos da América do Norte de 1789, com os seus mais de duzentos anos, possui apenas 27 emendas, enquanto a Constituição Federal brasileira, com menos de 30 anos de existência, já conta com quase uma centena de emendas.

É exatamente nesse panorama constitucional conturbado, complexo e confuso que o Código Tributário Nacional ainda sobrevive e acabou de completar meio século de vida. Idealizado durante o Período Militar, numa conjuntura política autoritária, o compêndio fiscal ressente-se de um espírito verdadeiramente democrático, recaindo em conflitos inconfessáveis com a Carta vigente. 


\section{Reforma Tributária e Alternativas para Promover a Efetiva- ção dos Direitos Fundamentais}

A reforma fiscal é desejo pujante manifestado pelos mais variados setores da sociedade brasileira na atualidade, notadamente em razão do imaginário coletivamente difundido, no sentido de que o sistema tributário nacional se revela ineficiente e incapaz de atender satisfatoriamente os interesses dos cidadãos. Desde a promulgação da Constituição Federal, em 1988, praticamente todos os Presidentes da República manifestaram o interesse político de avançar com reformas tributárias, sendo que, inclusive, diversas propostas de mudanças acabaram remetidas ao Congresso Nacional, embora todas tenham falhado após quase trinta anos de democracia. Não obstante, paralelamente às aspirações coléricas em favor das reformas fiscais estruturantes, vozes de renomadas autoridades do Direito Tributário ecoam na contramão desse discurso ordinário. Roberto Bocaccio Piscitelli (2003, p. 83), analisando a reforma tributária sob a perspectiva da "unanimidade de cada um", pondera que, como quase todos os assuntos relevantes da nossa realidade, o tema costuma ser tratado de forma parcial, apressada, distorcida e oportunista.

Conforme Paulo de Barros Carvalho, em entrevista concedida em janeiro de 2010, o sistema tributário funciona bem, arrecada adequadamente e não requer reparos. Para o eminente jurista, que se diz contrário a uma reforma estrutural, o avanço das propostas de alteração está cada vez mais distante, porquanto há mais de mil emendas substitutivas que precisam ser reorganizadas no Congresso, não havendo perigo, nesse cenário, de ocorrer uma reforma tributária profunda, que modifique os fundamentos do sistema tributário brasileiro. Carvalho argumenta que o sistema nacional reage bem sempre que é acionado, e o resultado ocorre dentro do esperado, ao contrário do que acontece em muitos países. Em realidade, Carvalho afirma que o problema tributário no Brasil repousa muito mais numa questão ética, em termos de justiça fiscal e distribuição equitativa da carga tributária. Para ele, uma coisa é afirmar que o sistema está bem organizado, que funciona bem; outra coisa muito diferente é dizer que funciona para o bem. Na atualidade, conclui o tributarista, o sistema tem 
funcionado apenas para aumentar a carga tributária, ou seja, ele não tem funcionado para o bem (CARVALHO, 2010).

De modo diametralmente oposto, outros juristas e economistas igualmente respeitados têm defendido que a reforma tributária é urgente e absolutamente indispensável para promover uma atualização do sistema de arrecadação brasileiro, sobretudo para que se possa enfrentar os desafios dos mercados globalizados. Um dos principais especialistas no tema do sistema tributário nacional, o economista Bernard Appy, que foi Secretário-Executivo e de Política Econômica do Ministério da Fazenda, durante o Governo do ex-Presidente Lula, defende que a reforma tributária é importante para o Brasil, principalmente para corrigir as grandes distorções do sistema de arrecadação, que acabam levando a uma baixa eficiência no funcionamento da economia, de maneira que a produtividade é bem menor do que poderia ser (APPY, 2016). Segundo Appy, o sistema fiscal brasileiro se tornou totalmente disfuncional e está roubando pontos do Produto Interno Bruto, notadamente pela sua complexidade e pelo enorme contencioso tributário provocado, o que gera uma aguda insegurança jurídica. Para o economista, há no Brasil um enorme custo de pagar os impostos, que vai muito além do seu próprio valor, ou seja, a dificuldade assombrosa de apurar o seu montante, representando um impacto financeiro adicionado em face das distorções que o modelo de tributário acarreta (APPY, 2016).

Outro estudioso que tem se dedicado à análise do sistema tributário brasileiro, o economista Fernando Rezende, sustenta que a reforma tributária é necessária e precisa sustentar-se num tripé de princípios: a simplicidade, a flexibilidade e a eficiência. Para Rezende, o Brasil nunca discutiu a reforma tributária em profundidade, porque o debate sempre deságua num combate (de ganhos e perdas), e nunca chegará a lugar algum. Por isso, segundo o economista, o sistema tributário deve reger-se a partir de premissas fundamentais, com regras claras e fáceis de serem compreendidas, e cujas normas possam ser ajustadas de forma mais simplificada, ou seja, com status de legislação infraconstitucional, sem comprometer ou criar embaraços ao desenvolvimento econômico, facilitando os processos de produção para que o país obtenha maior competitividade nos mercados internacional e doméstico (REZENDE, 2016). Em sentido convergente, 
um estudo encomendado pela Confederação Nacional da Indústria detectou que as principais deficiências do sistema tributário brasileiro vão muito além da elevada arrecadação, associando-se também ao exagerado número de tributos, à falta de simplicidade, à precariedade na estabilidade de regras, à violação dos direitos e das garantias do contribuinte, aos problemas de transparência, à insegurança jurídica, aos problemas nos prazos de recolhimento dos tributos (CNI, 2015).

Em suma, não há um consenso sobre a necessidade, muito menos acerca da intensidade, de reformas profundas no sistema tributário brasileiro. O que há, e isso parece inquestionável, é uma necessidade de ajustes específicos, de avanços pontuais, em prol do melhor equilíbrio no modelo de arrecadação e distribuição das riquezas. Afinal de contas, como afirmava Alfredo Augusto Becker, ainda no ano de 1963, o tributo é um instrumental revolucionário e decisivo da política fiscal, não representando somente um meio de arrecadar recursos financeiros para construir, mas também para destruir: a destruição das classes sociais privilegiadas e dos sistemas econômicos desumanos (BECKER, 1999, p. 19).

Analisando o sistema fiscal português, João Ricardo Catarino observa que Estado moderno prolifera crescentemente as suas atribuições e os seus domínios de intervenção, provocando efeitos sociais, econômicos e políticos perversos, como o aumento desmesurado das despesas públicas, a incidência irrazoável de encargos fiscais obrigatórios, a assunção de atividades para as quais o Estado não está vocacionado, além do empolamento da máquina pública, alargada, cara e ineficiente (CATARINO, 2009, p. 433-434). Em grande parte, os problemas do sistema fiscal de Portugal, apontados por João Ricardo Catarino, são semelhantes àqueles atualmente presenciados no Brasil, como exemplo os limites constitucionais e legais desajustados; a intrusão sistemática da Administração na vida privada dos contribuintes; a formatação de modelo fiscal pretensamente muito justo, mas pouco eficiente; a apresentação de soluções legais instrumentalizadas por meros impulsos políticos, as excessivas complexidades administrativas, os gastos públicos crescentes; a não reestruturação dos Estados, com a eternização das políticas públicas; a instabilidade das normas e a complexidade dos regimes fiscais; a incoerência das opções 
em matéria de política fiscal; a abusividade da adoção das taxas como impostos, dentre outros (CATARINO, 2009, p. 435-450).

De fato, a realidade brasileira modificou-se ao longo das duas últimas décadas e algumas adaptações fiscais precisam ser implementadas, justamente para acomodar as transformações sociais e o novo conjunto de direitos positivados pela Constituição Federal. No Brasil, vive-se num Estado de Direito que arrecada muito, é verdade, mas que igualmente promete muito em termos de efetivação dos direitos sociais, não se podendo esquecer que esse virtuoso modelo de bem-estar sugere um conjunto de receitas que devem ser compartilhadas por todos.

Mas, enfim, o que significa uma reforma tributária? De início, é importante pontuar que reformar implica reestruturar, de maneira mais ou menos aguda, a estrutura da legislação tributária, ou seja, o conjunto de normas que disciplinam a transferência de recursos privados para o setor público, com a finalidade de garantir a prestação satisfatória de serviços básicos à população. Fernando Rezende (2003, p. 155) aponta que uma das preocupações mais importantes em regimes federativos é assegurar o necessário equilíbrio entre a repartição de competências impositivas e a autonomia financeira dos entes políticos. Nesse sentido, considerando-se que o sistema tributário brasileiro se encontra esquadrinhado detalhadamente no texto constitucional, é corolário lógico que qualquer iniciativa de reforma tributária venha a exigir esforços normativos mais profundos, que atinjam propriamente o âmago da Carta Política. Nessa esteira, conforme sustenta Murilo de Oliveira Junqueira, entende-se por "reforma tributária" justamente o conjunto das três principais propostas de emenda constitucional sobre o tema: n. 175, de 1995, n. 41, de 2003, e n. 233, de 2008. E, para Junqueira, são três as razões que justificam esta escolha: em primeiro lugar, todas as propostas envolvem reformas constitucionais; em segundo lugar, as propostas foram apresentadas por Presidentes da República; por fim, e mais importante, essas três iniciativas foram reconhecidas como propostas de reforma tributária por atores políticos relevantes, como a grande mídia, o Poder Executivo e o Poder Legislativo (JUNQUEIRA, 2015, p. 94). 
Seja qual for o cenário, o problema mais alardeado quando se fala em reforma fiscal no Brasil é, sem sombra de dúvidas, o da tributação sobre os bens e serviços. Diferentemente da maior parte dos países do mundo, em que se onera essas bases econômicas com um tributo único, geralmente o imposto sobre o valor adicionado, no Estado brasileiro coexistem quatro tipos de exações ficais incidentes: o imposto sobre os produtos industrializados (IPI), de competência federal; o imposto sobre a circulação de mercadorias e serviços (ICMS), de competência estadual; o imposto sobre os serviços de qualquer natureza (ISS), de competência municipal; além das contribuições para o Programa de Integração Social e para o financiamento da Seguridade Social, ambas de competência federal. Com a Proposta de Emenda Constitucional n. 233, de 2008, pendente no Congresso Nacional, intentava-se atacar esse problema justamente com a simplificação do sistema tributário federal, a partir da criação de um imposto federal sobre o valor adicionado (IVA-F). Diante de uma análise bem superficial dessa proposta de reforma, é possível observar que a iniciativa de emenda constitucional tentou promover modificações substanciais no sistema tributário nacional, sendo essa a razão, talvez, que faça o projeto amargurar uma paralisia tão grande em sua tramitação, que segue esquecido, desde o ano de 2009, aguardando parecer da Comissão de Seguridade Social e Família.

Na ótica de José Sérgio da Silva Cristóvam, muito embora seja perfeitamente possível, do ponto de vista jurídico, a estruturação de um IVA-F a partir do somatório das hipóteses conferidas pela Constituição Federal, não se pode olvidar que, tanto política como economicamente, uma reforma com esse perfil apresenta-se praticamente impensável, havendo, em paralelo, quem se coloque frontalmente contrário a esse tipo de propositura, porquanto colocaria em risco a própria estrutura federativa introduzida pela atual ordem constitucional, que confere autonomia e competência tributária a todos os entes da Federação (CRISTÓVAM, 2006, p. 194). Por isso mesmo, Paulo de Barros Carvalho observa que, caso alguma modificação repercuta diretamente na autonomia dos Estados e dos municípios, ou nos princípios e nas garantias constitucionais, praticamente inviabilizará qualquer tipo de reforma estrutural (CARVALHO, 2010). Nesse sentido, imperioso notar que qualquer redistribuição drás- 
tica de receitas tributárias implicaria uma refundação aguda do pacto federativo, com a concomitante necessidade de redefinição das atribuições materiais de cada Ente Político, algo que parece bastante improvável em tempos de estabilidade institucional.

Atualmente, o debate a respeito da implementação da reforma tributária ganhou um novo fôlego, a partir da proposição capitaneada pelo deputado federal Luiz Carlos Hauly. Os contornos da proposta que se pretende apresentar ao Congresso Nacional, ainda em estágio preliminar, afinam-se com um modelo europeu de sistema tributário, assentando-se na instituição de um imposto de renda federal, um imposto sobre valor agregado e um imposto seletivo estaduais (mas com legislação federal), além de impostos municipais sobre o patrimônio. Analisando as linhas principais da proposta de reforma tributária defendida pelo deputado Hauly, percebe-se que alteração mais significativa e profunda afeta justamente as competências dos Estados e do Distrito Federal, com a previsão de um imposto sobre valor agregado, que deverá ser compatibilizado com um imposto seletivo monofásico sobre alguns produtos. A proposta prevê, ainda, a criação de um novo órgão dirigido por um Secretário Nacional, que agregará os Fiscos Estaduais e do Distrito Federal.

Por outro lado, não é possível negar que o Brasil atravessa uma importante crise em seu federalismo, capaz de abalar as próprias estruturas republicanas. No ordenamento brasileiro, conforme ensina Geraldo Ataliba (2007, p. 36), os princípios mais importantes são os da federação e da república, exercendo uma função capitular da mais transcendental relevância e determinando como devem ser interpretados os demais postulados, cuja exegese e aplicação jamais poderão ensejar menoscabo ou detrimento para a força, eficácia e extensão dos primeiros. Segundo Ataliba (2007, p. 37), exsurge a federação propriamente da associação de Estados para a formação de um novo Estado (o federal), com uma repartição rígida de atributos da soberania entre eles. Na atualidade, contudo, ninguém é capaz de negar a superior pujança econômica e política da União Federal no Estado brasileiro, sempre que comparada aos Estados-membros e, principalmente, aos municípios. Como uma das causas potencializadoras e representativas desse manifesto desequilíbrio, basta não se esquecer, por exemplo, de que ao longo da vigência da Constituição Federal houve uma 
hipervalorização de competências federais, notadamente para a instituição de contribuições sociais, cujas receitas não estão sujeitas à repartição constitucional, contrariamente ao que acontece com os impostos.

$\mathrm{O}$ ajuste federativo talvez represente o grande entrave para o avanço das reformas, sendo necessário reconhecer que o aprimoramento do sistema tributário nacional não pode ser pensado a partir de interesses particularizados de Entes Políticos, mas sim os da sociedade. Qualquer definição de competências sempre irá desencadear algum descontentamento, como é a hipótese das guerras fiscais hoje instaladas entre Estados e municípios. Sempre haverá um grupo de insatisfeitos. Ao contrário dos tempos da Ditadura Militar, quando as medidas vinham encomendadas pelos Generais e eram impostas de cima para baixo, na atualidade tudo acontece de uma maneira bem diferente. Paulo de Barros Carvalho lembra que na mesa de negociações tributárias estão sentados a União Federal, numa cabeceira, e o contribuinte, pequenininho, juntamente com os Estados, o Distrito Federal e mais de 5,5 mil municípios, na cabeceira oposta (CARVALHO, 2010). Certamente, esse é o grande e principal impasse para a consecução de uma ampla reforma democrática.

Nos últimos anos, acena-se com ajustes tributários bastante tímidos e sem grandes consequências concretas, tamanho é o vespeiro em que se quer evitar mexer. Como se costuma dizer no jargão popular, amputa-se o membro sem curar a enfermidade. Alfredo Augusto Becker, por ocasião da primeira edição de sua obra "Teoria Geral do Direito Tributário", lançada no início da década de 1960, já denunciava a caducidade precoce do direito tributário e a necessidade de uma metamorfose jurídica. Dizia o jurista que os governantes não admitem nenhuma reforma de estrutura e nem aceitam adaptar-se à realidade, pois as ideias novas os assustam e eles preferem continuar a governar à luz de experiências caducas. Para Becker, sempre que o Estado se mostra incapaz de adaptar-se às novas condições, ocorre uma ruptura nos quadros jurídicos antigos sob a forma de uma revolução social. Sustentava ele, naquela época, que só uma reforma radical poderia resolver a crise do direito tributário brasileiro. Becker observara que, ou o Estado quebrava o instrumental jurídico (as regras), ou este instrumental obsoleto acabaria ferindo as mãos do Estado. Às vezes, afirmara o tributarista, o Estado percebe tardiamente que o racional é 
renovar o instrumental jurídico. Outras vezes, a renovação é tão frequente que revela a ignorância do troglodita em criar o instrumento (BECKER, 2007, p. 505). Pelo jeito, após mais de cinquenta anos, a cegueira do Estado brasileiro não convalesceu.

Apesar de tudo, enquanto as reformas com maior densidade não prosperam e são postas em prática, medidas pontuais precisam ser empreendidas no sentido de promover algum reequilíbrio do sistema tributário. A regressividade do aparelho fiscal brasileiro é perversa, fazendo-o atuar como um Robin Hood às avessas, que tira o dinheiro dos pobres para entregar aos ricos, sendo que as grandes corporações, principalmente os bancos e as multinacionais, ocupam o topo da lista dos privilegiados. De acordo com Thomas Piketty, a arrecadação fiscal tornou-se regressiva, ou está a ponto de tornar-se, no topo da hierarquia das rendas na maioria dos países do mundo, de modo que as alíquotas de tributação elevadas para os mais pobres justificam-se pela importância dos impostos sobre o consumo e pelas contribuições sociais. Para Piketty, se a regressividade no topo da hierarquia social vier a se confirmar e se amplificar no futuro, é bem provável que ocorram consequências importantes para a dinâmica da desigualdade patrimonial e da concentração do capital (PIKETTY, 2013, p. 615). No Brasil, atualmente, conforme dados disponibilizados pelo Ministério da Fazenda, relativos ao ano de 2014, os tributos sobre o consumo representam $51,02 \%$ da arrecadação total, enquanto os impostos sobre a renda, $18,02 \%$, e os impostos sobre o patrimônio, apenas 4,17\%. Nos países integrantes da Organização de Cooperação e Desenvolvimento Econômico (OCDE), cuja média de arrecadação é muito pouco superior ao que se tributa no Brasil, ocorre exatamente o contrário, sendo que a arrecadação de impostos sobre o consumo é menor do que a arrecadação de impostos sobre a renda, enquanto é significativa a tributação que recai sobre o patrimônio (RFB, 2014).

Em realidade, uma das contas que pouquíssima gente gosta de pagar é a dos tributos, pois as pessoas esquecem, geralmente, que os impostos são também o preço da cidadania, conforme dissera o Justice Oliver Holmes, ao cunhar a frase "gosto de pagar impostos, com eles compro civilização" (NOGUEIRA, 1995, p. 124). O grande problema que se vislumbra no Brasil, porém, é que não basta arrecadar tributos, devendo-se 
cobrá-los dos cidadãos que têm capacidade contributiva. $\mathrm{O}$ atual modelo de tributação privilegia a taxação sobre o consumo, onerando principalmente as classes de renda mais baixa. Em outras palavras, incidindo a tributação sobre o consumo, o esforço dos pobres para pagar os seus impostos é muito maior que o dos ricos. O sistema inverso e desejável ocorre justamente quando a alternativa é por um sistema tributário progressivo, incidindo o imposto mais sobre o patrimônio e a renda. Clair Maria Hickmann (2007) destaca que, apesar do clamor social por uma reforma tributária, o debate fiscal ainda gira em torno da redução do tamanho da carga, e não da melhor distribuição entre as suas bases de incidência.

De outro lado, enquanto o sistema tributário nacional é condescendente com a taxação dos cidadãos mais pobres no Brasil, a problemática agrava-se ainda mais com a sua falta de neutralidade, que constitui uma obrigação negativa do Estado de não interferir na livre concorrência por meio da tributação, ao mesmo tempo em que deve atuar positivamente para prevenir ou restaurar, quando for o caso, a igualdade de condições competitivas no mercado. Num Estado Democrático de Direito, o princípio de neutralidade fiscal deve atuar como um vetor da equidade, interferindo minimamente na atividade econômica e promovendo a justiça social.

A modernização do sistema tributário brasileiro, tornando-o mais igualitário materialmente, precisa ser um ideal reconhecido pela sociedade e perseguido pelas instituições. Estudos recentes comprovam que o Brasil é o paraíso tributário para os chamados super-ricos. E nem é preciso maiores análises para entender que um dos motivos mais importantes dessa distorção é exatamente a isenção de tributos sobre os lucros e dividendos, concedida no ano 1995, durante o Governo do ex-Presidente Fernando Henrique Cardoso. Segundo o levantamento de Gobetti e Orair (2016, p. 17), a estrutura do imposto sobre a renda no Brasil é pouco progressiva e favorece a concentração de riqueza. De acordo com esse estudo, a alíquota média, considerando a renda total dos brasileiros, é de $7 \%$ entre os $0,05 \%$ cidadãos mais ricos, de modo que esses pagam menos imposto, proporcionalmente, que as 4 milhões de pessoas que ganham anualmente entre R\$ 131 mil e R\$ 1 milhão, incluindo algumas frações da classe média, cuja alíquota média é de aproximadamente $12 \%$. Diante desse panorama, caracterizado por benefícios tributários ao rendimento 
do capital, entre outras assimetrias nocivas à coletividade, o Brasil lidera o ranking das maiores concentrações de renda, senão a maior, entre todos os países do mundo (GOBETTI; ORAIR, 2016, p. 17-18). Curioso notar que, entre os 34 países integrantes da OCDE, apenas a Estônia também isenta os dividendos, sendo razoável retomar essa agenda da progressividade, há muito tempo negligenciada no país, blindando fortunas de bilhões de reais exatamente dos brasileiros mais abastados.

A grande realidade é que o Brasil é um país que arrecada bastante, mas que também gasta muito. E gasta muito mal. $O$ retorno da tributação no Brasil é pífio, se considerado que o país ocupa a posição de nona economia mundial. Contudo, apesar da elevada carga de impostos, a tributação brasileira não está completamente desalinhada dos principais sistemas de arrecadação do mundo. Por certo, a forma de tributar é que está equivocada. Alfredo Augusto Becker já denunciava, há tempos, aquilo que chamou de naufrágio fiscal, afirmando que a tributação irracional dos últimos anos conduziu os contribuintes, em especial os assalariados, a tal estado que, hoje, só lhes resta a tanga. Dizia Becker, ademais, a respeito das leis do imposto de renda, que eram tão contínua e frequentemente modificadas, que o Governo já nem mais se dava ao trabalho de consolidar toda essa proliferação de alterações em um novo Regulamento do Imposto de Renda, cuja sigla, atualmente, é uma retumbante ironia: RIR (BECKER, 1999, p. 17). Os anos passaram e a ironia persiste.

Enfim, tantas alternativas somam-se nesse cenário de possíveis reformas. O imposto sobre as grandes fortunas, por exemplo, mesmo apresentando graves problemas na experiência comparada e sendo a sua implementação duvidosa, jamais recebeu um tratamento sério ou foi objeto de debates mais profundos, mesmo que sob a forma de uma progressividade mais incisiva do imposto sobre a renda. Talvez porque, no Brasil, não se queira levar essa discussão adiante. Paralelamente, as heranças milionárias recebidas por cidadãos em solo brasileiro sofrem uma tributação absolutamente irrisória, exigida pelos Estados, muito embora os beneficiários embolsem esses legados não pelo fruto do seu próprio trabalho, mas pela mera perpetuação da transferência de patrimônios familiares. O imposto único, por sua vez, defendido incisivamente por alguns especialistas, foi igualmente rechaçado durante toda a história da tribu- 
tação brasileira, muitos deles dizendo que contraria os interesses de grupos poderosos e que lucram com o caos tributário atual. Segundo Aliomar Baleeiro (2010, p. 283), no entanto, trata-se de uma utopia que seduziu espíritos lúcidos durante algum tempo, mas que, em sociedades profundamente diferenciadas como as do nosso tempo, seria difícil obter-se um imposto que atingisse eficazmente todos os contribuintes em sua imensa diversidade. Ou seja, muitos caminhos existem para que se possa debater consistentemente a reforma do sistema tributário no Brasil. O que falta é vontade.

\section{Conlusão}

A necessidade de uma reforma tributária profunda não é unanimidade no Brasil. Paralelamente, é fato que o cidadão brasileiro sofre com a indolência e com o medo da efetivação de mudanças contundentes. A cultura de corrupção e conchavos fortemente arraigada na sociedade brasileira, alheia aos desígnios republicanos, retarda uma discussão que já não suporta mais esperar. $\mathrm{O}$ sistema tributário brasileiro é regressivo e onera quem menos pode pagar as exigências fiscais, inexistindo interesse e fundadas razões para que os atores econômicos mais influentes realmente busquem uma atualização estrutural do modelo.

O Código Tributário Nacional, já idoso e capenga, logrou diversos êxitos ao longo de sua existência, resultado de um trabalho desenvolvido por valorosos juristas da época de sua publicação. Mas o tempo passou e o texto cedeu. Há necessidade de uma atualização da legislação, compatibilizada com o conjunto de garantias e direitos solenemente anunciados pela vigente Constituição Federal.

Nos dias atuais, a ideia de bem comum decorre de uma relação ética prescrita no texto constitucional, pautada, sobretudo, numa relação colaborativa entre Fisco e contribuintes. Modernamente, é preciso encarar a relação tributária sob uma ótica consensual, ao contrário do que ocorria no passado, quando a tributação era impositiva. Deve-se reconhecer que o cidadão sustenta o Estado, e não o contrário, de modo que o direito tribu- 
tário existe para exercer muito mais um papel de proteger o contribuinte do que arrecadar.

\section{Referências}

\section{APPY, Bernard. Entrevista concedida para a Associação Brasileira de} Bares e Restaurantes. [2016]. Disponível em: <http://www.abrasel.com. br/atualidade/entrevistas/3111-reforma-tributaria-para-o-brasil-crescer. html>. Acesso em: 13 jan. 2017.

. Entrevista concedida para Dimalice Nunes, jul. 2016.

Disponível em: <http://www.cartacapital.com.br/economia/201cosistema-tributario-se-tornou-totalmente-disfuncional201d $>$. Acesso em: 13 jan. 2017.

AQUINO, Santo Tomás de. Suma Teológica IV: Os Hábitos e as Virtudes; Os Dons do Espírito Santo; Os Vícios e os Pecados; A Lei Antiga e a Lei Nova; A Graça. São Paulo: Edições Loyola, 2005. ASSOCIAÇÃO COMERCIAL DE SÃO PAULO. Impostômetro, 2016. Disponível em: $<$ https://impostometro.com.br/>. Acesso em: 13 jan. 2017.

ATALIBA, Geraldo. República e Constituição. 2. ed. atual. por Rosolea Miranda Folgosi. São Paulo: Malheiros, 2007.

BALEEIRO, Aliomar. Uma Introdução à Ciência das Finanças. 17. ed. rev. e atual. por Hugo de Brito Machado Segundo. Rio de Janeiro: Forense, 2010.

BALTHAZAR, Ubaldo Cesar. História do Tributo no Brasil. Florianópolis: Fundação Boiteux, 2005.

BANCO MUNDIAL. Doing Business, 2015. Disponível em: $<$ http:// portugues.doingbusiness.org/data/exploretopics/paying-taxes $>$. Acesso em: 13 jan. 2017.

BECHO, Renato Lopes. Filosofia do Direito Tributário. São Paulo: Saraiva, 2009. 
BECKER, Alfredo Augusto. Carnaval Tributário. 2. ed. São Paulo: Lejus, 1999.

. Teoria Geral do Direito Tributário. 4. ed. São Paulo: Noeses, 2007.

BOBBIO, Norberto; MATTEUCCI, Nicola; PASQUINO, Gianfranco. Dicionário de Política. v. I. Trad. Carmen C. Varriale et al. 13. ed. Brasília: Editora Universidade de Brasília, 2010.

CARRAZZA, Roque Antônio. Curso de Direito Constitucional Tributário. 26. ed. São Paulo: Malheiros, 2010.

CARVALHO, Paulo de Barros. Entrevista concedida a Alessandro Cristo, 2010. Disponível em: < http://www.conjur.com.br/2010-jan-17/ entrevista-paulo-barros-carvalho-professor-direito-tributario $>$. Acesso em: 13 jan. 2017.

CATARINO, João Ricardo. Para uma Teoria Política do Tributo. 2. ed. rev., ampl. e actual. Lisboa: Ciência e Técnica Fiscal, Centro de Estudos Fiscais, Ministério das Finanças e da Administração Pública, 2009.

CONFEDERAÇÃO NACIONAL DA INDÚSTRIA. Indicadores CNI, Ano 16, Número 5, ago. 2015. Disponível em: <http://arquivos. portaldaindustria.com.br/app/cni_estatistica_2/2015/08/28/189/ SondEspecial_Tributacao_Agosto2015.pdf >. Acesso em: 13 jan. 2017. CRISTÓVAM, José Sérgio da Silva. Direito tributário comparado no Mercosul. In: BALTHAZAR, Ubaldo Cesar (Org.). O Tributo na História: da Antiguidade à Globalização. Florianópolis: Fundação Boiteux, 2006. p. 177-202.

DELFIM NETTO, Antônio. Entrevista concedida a Aguinaldo Novo, 2014. Disponível em: $<$ http://oglobo.globo.com/economia/delfimnetto-sobre-atuacao-no-regime-militarnao-tenho-nada-do-que-mearrepender-11959575>. Acesso em: 21 dez. 2016.

GOBETTI, Sérgio Wulff; ORAIR, Rodrigo Octávio. Tributação e distribuição da renda no Brasil: novas evidências a partir das declarações tributárias das pessoas físicas. IPC-IG Working paper. n. 136. Brasília, International Policy Centre for Inclusive Growth, fev. 2016, 


\section{HAULY, Luiz Carlos. Principais Linhas da Proposta de Reforma} Tributária, 2017. Disponível em: $<$ http://www2.camara.leg.br/atividadelegislativa/comissoes/comissoes-temporarias/especiais/55a-legislatura/ reforma-tributaria/documentos/outros-documentos/resumo-hauly>. Acesso em: 9 out. 2017.

HICKMANN, Clair Maria. Quando os pobres pagam pelos ricos. Le Monde Diplomatique Brasil, set. 2007. Disponível em: $<$ http:// diplomatique.org.br/?s=quando + os + pobres + pagam $>$. Acesso em: 16 jan. 2017.

HOBBES, Thomas. Leviatã: ou matéria, forma e poder de uma República Eclesiástica e Civil. Trad. João Paulo d Monteiro e Maria Beatriz Nizza da Silva. São Paulo: Martins Fontes, 2003.

HUMBOLDT, Wilhelm von. Os Limites da Ação do Estado. Trad. Jesualdo Correia. Rio de Janeiro: Liberty Fund, Topbooks, 2004.

JUNQUEIRA, Murilo de Oliveira. O nó da reforma tributária no Brasil (1995-2008). Rev. bras. Ci. Soc. [on-line], v. 30, n. 89, p. 93-113. 2015. Disponível em: <http://dx.doi.org/10.17666/308993-113/2015>. Acesso em: 16 jan. 2017.

LIMA, Edilberto Carlos Pontes. Reforma tributária no Brasil: entre o ideal e o possível. Brasília: IPEA - Instituo de Pesquisa Econômica Aplicada, 1999.

MILL, John Stuart. El Utilitarismo: un sistema de la lógica. Trad. Esperanza Guisán. Madrid: Alianza Editorial, 1984.

MINISTÉRIO DO PLANEJAMENTO, ORÇAMENTO E GESTÃO. Evolução recente da carga tributária federal, nov. 2015. Disponível em: <http://www.planejamento.gov.br/secretarias/upload/arquivo/assec/ evolucao-recente-da-carga-tributaria-federal-3.pdf $>$. Acesso em: 13 jan. 2017.

NOGUEIRA, Ruy Barbosa. Curso de Direito Tributário. 14. ed. atual. São Paulo: Saraiva, 1995.

PESSÔA, Leonel Cesarino. O Princípio do Benefício como Critério de Justiça Tributária: as diferentes interpretações. In: XVII ENCONTRO 
PREPARATÓRIO PARA O CONGRESSO NACIONAL DO CONPEDI, 2008, Salvador. Anais... Salavador, 2008. Disponível em: $<$ http://www. publicadireito.com.br/conpedi/anais_salvador.html $>$. Acesso em: 12 jan. 2017.

PISCITELLI, Roberto Bocaccio. Reforma Tributária: a unanimidade de cada um. In: MORHY, Lauro (Org.). Reforma tributária em questão. Brasília: UnB, 2003. p. 83-92.

PIKETTY, Thomas. O Capital no século XXI. Trad. Monica

Baumgarten de Bolle. Rio de Janeiro: Editora Intrínseca, 2013. e-book. Disponível em: $<$ https://fernandonogueiracosta.files.wordpress. com/2015/08/o-capital-no-secc81 culo-xxi-thomas-piketty.pdf.> Acesso em: 17 jan. 2017.

RECEITA FEDERAL DO BRASIL. Carga Tributária no Brasil 2014: análise por Tributos e Bases de Incidência. Brasília, out. 2015.

REZENDE, Fernando. Entrevista concedida a Verene Wolke, mar. 2016. Disponível em: <http://www.portaldaindustria.com.br/cni/ imprensa/2016/03/1,82276/reforma-tributaria-e-decisiva-para-o-brasilcrescer-e-enfrentar-a-concorrencia-global.html>. Acesso em: 12 jan. 2017. REZENDE, Fernando. Reforma Tributária e Federação. In: MORHY, Lauro (Org.) Reforma tributária em questão. Brasília: UnB, 2003. p. 153-165.

ROSA JR., Luiz Emygdio F. Manual de Direito Financeiro \& Direito Tributário. 20. ed. Rio de Janeiro: Renovar, 2007.

SMITH, Adam. A Riqueza das Nações: investigação sobre sua natureza e suas causas. v. II. Trad. Luiz João Baraúna. São Paulo: Nova Cultural, 1996.

TORRES, Ricardo Lobo. A Idéia de Liberdade no Estado Patrimonial e no Estado Fiscal. Rio de Janeiro: Renovar, 1991.

ZAVARIZI, Índio Jorge. A Fiscalidade no Brasil República. In: BALTHAZAR, Ubaldo Cesar (Org.). O Tributo na História: da Antiguidade à Globalização. Florianópolis: Fundação Boiteux, 2006. p. 123-135. 
Carlos Henrique Machado é doutorando do Programa de Pós-Graduação em Direito da UFSC. Mestre em Direito pela UFSC. Advogado e professor. E-mail: oab18157@gmail.com.

Endereço profissional: Universidade Federal de Santa Catarina Centro de Ciências Jurídicas. Programa de Pós-Graduação em Direito Campus Universitário, s/n TrindadeFlorianópolis - SC. CEP: 88040-900.

\section{Ubaldo Cesar Balthazar}

Doutor em Direito pela Universidade Livre de Bruxelas. Mestre em Direito pela UFSC. Professor dos Cursos de Graduação e Pós-Graduação da UFSC.

E-mail: ubalth@gmail.com.

Endereço profissional: Universidade Federal de Santa Catarina Centro de Ciências Jurídicas. Programa de Pós-Graduação em Direito Campus Universitário, s/n Trindade Florianópolis - SC. CEP: 88040-900. 